\title{
Miguel Maldonado. (2010). Los buenos oficios. Responso a Los de- monios y los días de Rubén Bonifaz Nuño. México: Consejo Nacio- nal para la Cultura y las Artes / Gobierno del Estado de Puebla.
}

Jocelyn Martínez Elizalde

FFyL-UNAM

Los demonios y los días (1956) de Rubén Bonifaz Nuño es un poemario particularmente indispensable en la obra del poeta veracruzano y en la poesía mexicana en general. En este libro, Bonifaz Nuño retrata, la decadencia de una ciudad y la soledad de los hombres que en ella se pasean, en ocasiones tristísimos por las calles y los camiones de la urbe nocturna y en otras, entretenidos por la falsa diversión del cine, la fiesta y las limonadas.

Dos son los temas que invaden el poemario de Bonifaz Nuño: en primer lugar, las formas de comunicación - siempre fallidas - entre los hombres y, en segundo lugar, el oficio del poeta y sus alcances.

Constantemente el sujeto lírico de los poemas de Los demonios y los días hace referencia a cartas que nunca llegan, a voces que no se escuchan, a oídos sordos, la incomunicabilidad parece ser lo único que los hombres tienen en común, tal como se lee en el poema 22 " ¿Para qué nos sirven las palabras/ si no son capaces de nombrar, si no pueden/ jamás ser oídas?" (Bonifaz Nuño, 1979:138) O más adelante en el poema 26: "Pero nadie escucha, no entiende nadie/ y cada quien sigue como puede/ su triste monólogo de idiota."

De acuerdo con Los demonios y los días es la voz del poeta, junto con el sacrificio y el esfuerzo cotidiano, lo que debe sacar a la humanidad de su eterno mutismo a través del diálogo y de la poesía; pero no se trata de un trabajo privilegiado, es sólo un oficio más como el del cartero o el del albañil, cuyos objetivos son, incluso, semejantes: procurar la comunicación óptima entre los hombres o el tender puentes. En el poema 2 de Los demonios y los días se encuentra justo la unión entre este libro y Los buenos oficios de Miguel Maldonado: ${ }^{2}$

\footnotetext{
Ay, amigos míos; señoras, señores que no me escuchan: hay oficios buenos, ${ }^{*}$ necesarios a todos;
}

1 Bonifaz Nuño, R. (1979). De otro modo lo mismo. México: Fondo de Cultura Económica.

2 Maldonado, M. (2010). Los buenos oficios. responso a los demonios y los días de Rubén Bonifaz Nuño. México: Consejo Nacional para la Cultura y las Artes.

* Las cursivas son mías. 
el que hace las camas y las mesas, el que siembra, el que reparte cartas, tienen un lugar entre todos: sirven.

Yo también conozco un oficio:

Aprendo a cantar. Yo junto palabras justas

en ritmos distintos. Con ellas lucho,

hallo la verdad a veces,

y busco la gracia para imponerla.

Miguel Maldonado (Puebla, México, 1976) es ensayista y poeta, obtuvo el Premio Nacional de Poesía Joven Gutierre de Cetina, 2006. A Los buenos oficios. Responso a Los demonios y los días de Rubén Bonifaz Nuño le anteceden otros tres libros de poesía. Los buenos oficios de Maldonado es un ejercicio de intertextualidad y un proceso de apropiación y recreación del poemario de Bonifaz Nuño. Desde el título se hace evidente, por la alusión a Los demonios y los días; se continúa con el epígrafe que pertenece al último poema del libro del poeta veracruzano y se prolonga a lo largo de todo el poemario con una fragmento de cada poemas de Los demonios y los días que precede a su vez a los de Los buenos oficios.

El epígrafe se constituye como el eje de los poemas de Miguel Maldonado, en él se encuentra su objetivo: responder al llamado del poeta. El epígrafe dice: "Estoy escribiendo para que todos / puedan conocer mi domicilio, / por si alguno quiere contestarme." Más adelante el poema continúa con la insistencia del enunciado apelativo: "Yo sólo pretendo hablar con alguien, / decir y escuchar. No es gran cosa."

Miguel Maldonado, consciente de su "buen oficio" de poeta, contesta no sólo con una epístola, sino con un poemario en el que se nota no únicamente la influencia estilística de su destinatario, más importante aún, es evidente la recreación que el poeta poblano está brindando a la poesía de Bonifaz Nuño.

Entre las semejanzas estilísticas con Los demonios y los días, Los buenos oficios contiene, en primer lugar, la consciencia del otro, la empatía por el abandonado, por el solitario, por el necesitado:

Hay cosas que no nos serán dadas
cosas que quizá siquiera existen
no nos llegarán y esto nos duele
Pero son una ocasión para el abrazo
La presencia de esta falta nos coloca
en una hermandad de circunstancias.

En segundo lugar, pueden hallarse diversas metáforas relacionadas con lo cotidiano del espacio urbano o del hogar: 
Sentimos que nos vamos vaciando

silenciosamente

como una fina fuga de agua

oculta en las tuberías de una casa.

Otra de las temáticas típicas que comparten Bonifaz Nuño y Miguel Maldonado es la reiteración de la pobreza, en algunos momentos la desesperanza y en otros la solidaridad:

¡Cuánta vida salta en medio de esta podredumbre!

El brillo de unos ojos en una cara sucia

Los tiernos tobillos con zapatos rotos del tacón

Los héroes vencidos por el vencimiento de pago

Los empeños de los niños empeñando su niñez.

Asimismo, se encuentra la conciencia del oficio del poeta y de la importancia de la poesía en el mundo, no como un ideal, sino como una necesidad cotidiana:
Yo no sé si valga más hacer poemas
que reparar muebles descompuestos
que tratar de dar arreglo a cosas justas
yo sé que la necesidad nos ocupa
pero afuera no se está bien.

Como mencioné anteriormente, lo más valioso del poemario es la recreación de metáforas que, si bien están imitando el estilo bonifaciano, "imponen la gracia" de la poesía creando nuevos efectos con objetos comunes:

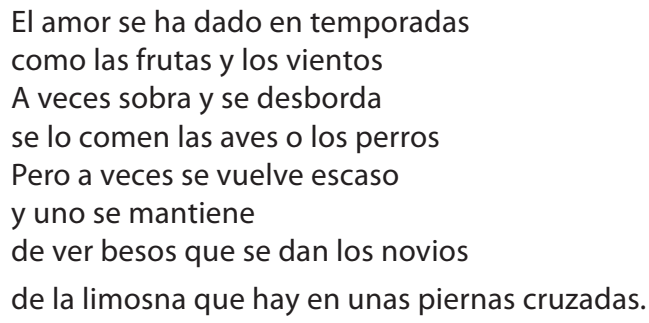

Casi medio siglo después, el poeta por fin recibió respuesta, tristemente hay que mencionar que ahora Rubén Bonifaz Nuño padece de una cruel ceguera y de una sordera absoluta, mismas que le impedirían escuchar o leer cualquier carta, no obstante, esta respuesta va dirigida no sólo al poeta, si no al hombre común, al del buen oficio. 
Decires es una publicación editada en línea y de libre acceso alojada en <http://www.decires.unam.mx> del Centro de Enseñanza para Extranjeros de la UNAM. Ciudad Universitaria, junio 2011. El cuidado de la edición estuvo a cargo de Ariadna G. Vaca Moro. Diseño de interiores y formación tipográfica: Yvetthe $P$. Rendón Rahal.

Diseño de portada: Yvetthe P. Rendón Rahal. 